$\mathcal{S}_{\text {https://doi.org/10.3765/sp.12.10 }}^{\text {Semantics \& Pragmatics Volume 12, Article 10: 1-24, } 2019}$

\title{
Where is the destructive update problem?*
}

\author{
Simon Charlow \\ Rutgers University
}

Submitted 2018-05-29 / First decision 2018-06-10 / Revision received 2018-12-10 / Accepted 2019-03-04 / Published 2019-11-15 / Final typesetting 2023-04-26

\begin{abstract}
I critically examine several objections to 'destructive update' of assignment functions in dynamic theories of anaphora, using a modular compositional treatment of the static/dynamic divide to highlight what static and dynamic approaches to assignment functions have in common, and how they differ.
\end{abstract}

Keywords: dynamic semantics, assignment functions, variables

\section{Overview}

This paper attempts to clarify the sense in which 'destructive update' of assignment functions is problematic for dynamic theories of anaphora. I argue that it is difficult to locate any undesirable empirical predictions associated with destructive update. Texts with destructive updates have respectable truth conditions, and destructive update does not appear directly responsible for any under- or over- generation issues.

I suggest that, on reflection, these results are basically unsurprising. Destructive update is, after all, a characteristic feature of how binding is perpetrated in standard static systems (including first-order logic and $\lambda$-calculus). To draw this point out formally, I sketch a novel modular account of the static/dynamic divide, arguing that dynamic systems with destructive update inherit their approach to assignment modification directly from static systems, but combine it with a view of assignments as information. I suggest

* Thanks to Maria Aloni, David Beaver, Dylan Bumford, Paul Elbourne, Simon Goldstein, Daniel Rothschild, Anna Szabolcsi, and two anonymous referees for discussions and comments that helped me see things more clearly.

(C)2019 Simon Charlow

This is an open-access article distributed under the terms of a Creative Commons Attribution License (https://creativecommons.org/licenses/by/3.o/). 
that it's this constellation of formal properties which is ultimately responsible for the intuition that destructive update is problematic. I conclude by considering whether and how the failures of antisymmetry characteristically associated with destructive update might be conceptually, empirically, and technically fraught.

\section{Dynamic interpretation}

In compositional dynamic reconstructions of DRT, sentences denote relations on assignments, type $s \rightarrow s \rightarrow t$ (e.g., Barwise 1987, Rooth 1987, Groenendijk \& Stokhof 1991a, and Muskens 1996; Kamp 1981 and Kamp \& Reyle 1993 are classic references on DRT). For example, sentence (1) is associated with the dynamic meaning in (2). This relation maps an input assignment $g$ into a set of possible outputs, each associating the index 3 with a man who walked in the park (and otherwise just like $g$ ). ${ }^{1}$

(1) $\quad \mathrm{A} \mathrm{man}^{3}$ walked in the park.

(2) $\lambda g \cdot\left\{g^{3 \rightarrow x} \mid \operatorname{man} x \wedge\right.$ witp $\left.x\right\}$

The idea is that (2) models how (1) updates the value associated with the index 3 in context. Processing (1) means coming to associate 3 with a man who walked in the park.

The principal motivation for dynamic semantics is that indefinites can bind pronouns they don't scope over (i.e., c-command at LF). If (1) is continued with (3), it's possible and natural to hear the indefinite and the pronoun as covalued, though it's unlikely the indefinite could ever come to have scope over a pronoun in a separate sentence.

(3) $\mathrm{He}_{3}$ whistled.

Dynamic semantics allows binding, even without scope. Sentences denote relations storing information about the values of variables in their output assignments. Dynamic conjunction, in (4), links two dynamic sentence meanings together by composing them qua relations: the left conjunct outputs a set of potentially updated assignments $\llbracket \phi \rrbracket g$, which are fed one-by-one as inputs to the right conjunct, yielding new sets of potentially updated assignments, which are finally unioned to complete the update.

(4) $\quad \llbracket \phi . \psi \rrbracket:=\lambda g . \cup_{h \in \llbracket \phi \rrbracket g} \llbracket \psi \rrbracket h$

1 The dynamic system used in this paper is a Montagovian refactoring of Groenendijk \& Stokhof's (1991a) DPL. 
Where is the destructive update problem?

Dynamic conjunction guarantees that the right sentence in a conjunction is evaluated in the anaphoric context established by the left sentence. If (3) has the semantics in (5) (where ' $g_{3}$ ' names the individual $g$ associates with the index 3), dynamically conjoining (2) and (5) yields (after a few simplifications) the meaning in (6), which covalues the walking man and the whistler, as desired. Binding transpires because the left conjunct outputs assignments that associate 3 with a man who walked in the park, which dynamic conjunction passes as inputs to the right conjunct.

(5) $\lambda g \cdot\{g\}$ if whistled $g_{3}$ else \{\}

(6) $\lambda g \cdot\left\{g^{3 \rightarrow x} \mid \operatorname{man} x \wedge\right.$ witp $x \wedge$ whistled $\left.x\right\}$

Truth conditions can be extracted from dynamic sentence meanings by existentially quantifying over outputs at a given input assignment, as in (7):

(7) $\quad K$ is True at $g \Longleftrightarrow K g \neq\{\}$

According to (7), (2) is True at an input $g$ iff a man walked in the park; (5) is True at $g$ iff $g_{3}$ whistled; and (6) is True at $g$ iff a man who walked in the park whistled.

\section{Destructive update}

It is frequently suggested that the simplest dynamic systems - those identifying sentence meanings with relations on total assignments - have an undesirable feature: indices can be chosen in a way that allows information about the values of variables to be lost (see, e.g., Vermeulen 1993, 1995, Groenendijk, Stokhof \& Veltman 1996, van Eijck 2000, 2001, Beaver 2002, Nouwen 2003, Brasoveanu 2007, Lebedeva 2012, Haug 2014, and Nouwen et al. 2016). This feature of dynamic theories goes by various names - e.g., the destructive update problem, the overwrite problem, or the downdate problem.

Consider (8). This text has two indefinites in separate sentences, bearing the same index. Given the obvious dynamic meanings for the individual sentences and the semantics for dynamic conjunction in (4), this text ends up associated with the interpretation in (9). The first indefinite updates 6 to be associated with some linguist who entered the room. The second tosses out the work of the first, reassigning 6 to a linguist who was already there. After the second sentence is processed, the entering linguist has been written out of the anaphoric picture: $\left(g^{6 \rightarrow x}\right)^{6 \rightarrow y}$ is equivalent to $g^{6 \rightarrow y}$, and so any 
subsequent pronouns will be unable to refer back to the first indefinite.

(9) $\quad \lambda g .\left\{\left(g^{6 \rightarrow x}\right)^{6 \rightarrow y} \mid\right.$ linguist $x \wedge$ entered $x \wedge$ linguist $y \wedge$ there $\left.y\right\}$

A characteristic diagnosis of the situation is given by Vermeulen (1995: p. 437): "[T]he re-use of a variable name can have nasty side effects. For whenever we give a new use to a variable name...we are forced to forget the information that was previously attached to that name." Groenendijk, Stokhof \& Veltman (1996: p. 195) pile on: "The introduction of such downdates complicates the formulation of the basic semantic notions." As we will see, however, destructive updates are not all that nasty - indeed, I argue, destructive updates are not empirically problematic, resulting as they do from a dynamic extension of anodyne static notions - and such complications arguably do not arise.

A standard way of avoiding destructive update uses partial assignments to gauge whether an incoming assignment already harbors values for any indices a given sentence is looking to update. If so, some sort of non-default behavior is triggered - for instance, undefinedness, as in (10). ${ }^{2}$ Proposals along these lines have been mooted by Dekker (1993), van den Berg (1996), Brasoveanu (2007), and Haug (2014), and others.

$$
\lambda g: \neg \exists y .(6, y) \in g \cdot\left\{g^{6 \rightarrow y} \mid \text { linguist } y \wedge \text { there } y\right\}
$$

A related approach replaces assignments with sequences of individuals, updated via a monotonic operation like sequence extension, as in (11), where ' $e^{-} y$ ' is the sequence $e$ extended with the individual $y$. Proposals along these lines have been discussed by Vermeulen (1993, 1995), Dekker (1994), Groenendijk, Stokhof \& Veltman (1996), Bittner (2001), van Eijck (2001), de Groote (2006), Nouwen (2007), Brasoveanu (2007), Charlow (2014), Bumford (2015), and Nouwen et al. (2016), and others. ${ }^{3}$

$$
\lambda e .\left\{e^{-} y \mid \text { linguist } y \wedge \text { there } y\right\}
$$

Both approaches rule out destructive updates: (10) forces indices to be novel in context, on pain of undefinedness, and (11) doesn't mention indices at all.

2 In case the notation is unfamiliar, (10) is a function defined only for $g$ 's which assign no value to 6 .

3 In the 'referent systems' of Vermeulen (1995), the link between a variable and its value can be destroyed or overwritten, but the value itself is retained within the referent system. See Groenendijk, Stokhof \& Veltman 1996 and Nouwen 2007 for discussion of related systems, along with pertinent empirical discussion. 
Where is the destructive update problem?

\section{Truth conditions}

Importantly, destructive update does not yield problematic truth conditions. Recalling our characterization of truth-at-an-assignment in (7), we observe that, at any input $g$, (9) returns an output iff (i) there's a linguist who entered the room, and (ii) there's a linguist who was already there. If (i) isn't met, then linguist $x \wedge$ entered $x$ cannot be satisfied; if (ii) isn't met, then linguist $y \wedge$ there $y$ fails. These are, as the reader can check, the same truth-conditions as we'd derive with contra-indexed indefinites - or, indeed, within a static generalized-quantifier theory. In particular, coindexing indefinites does not cause them to be covalued - a good result since (8) clearly lacks any such readings.

This isn't to say there could never be a theory where coindexed indefinites were covalued. Indeed, avoiding spurious covaluation is an important reason Heim's (1982) File Change Semantics requires indefinites' indices to be novel. A similar state of affairs is seen in DRT, where the construction algorithm for discourse representation structures must see to it that indefinites are associated with novel indices (Kamp \& Reyle 1993: p. 84). There are also static theories that sometimes covalue coindexed indefinites: Reinhart's (1997) choice-functional theory covalues any two indefinites with the same descriptive content when they are interpreted via the same choice function (cf. Geurts 2000: p. 734).

The fact that the theories mentioned in the previous paragraph can, in principle, covalue multiple indefinites cannot, however, be blamed on destructive update. Indeed, in each of those theories, indefinites function as variables - i.e., as anaphoric: Heimian indefinites are anaphoric to an existential closure operator; indefinites in DRT result in the construction of conditions anaphoric to a top-level discourse referent; and choice-functional indefinites are either anaphoric to an existential closure operator (Reinhart 1997, Heim 2011), or to a contextually provided choice function (Kratzer 1998). This anaphoric treatment of indefiniteness is the locus of problematic co-construal readings, which arise precisely when two indefinites are anaphoric in the same way. Indeed, having indefinites update assignments, destructively or otherwise, is something like the formal opposite of anaphora updating assignments creates anaphoric possibilities instead of consuming them - and is thus an efficient way to avoid covaluation of indefinites. 
Simon Charlow

\section{Under-generation?}

Are there any under-generation issues associated with destructive updates? Again, the answer seems to be negative. It is certainly true that after uttering a linguist entered the room; a linguist was already there, subsequent pronouns will be able, in principle, to refer back to either linguist - for example, in a sentence like she greeted him. It's also true that (9) doesn't allow this. The only linguist available after both sentences have been processed is the second one; the first has been dismissed from the conversational record.

However, under-generation is a property of theories: a theory undergenerates iff it's inconsistent with some empirical observation. And while (8) and (9) don't make enough anaphoric possibilities available in conversational contexts where we seek to refer back to both linguists, it's nevertheless clear how theories with destructive update cope: they generate another parse, just like (8) but with contra-indexed indefinites. Such a parse is consistent with the actual utterance, which has no overtly expressed indices. ${ }^{4}$

Another potential under-generation issue, discussed by Brasoveanu (2007: p. 113)and Haug (2014: p. 463), involves sentences with an indefinite interpreted within the scope of a distributive conjunction, like the reading of (12) on which Bill and Sue each own a donkey.

$$
\text { Bill }^{1} \text { and Sue }{ }^{2} \text { own a donkey }{ }^{3} \text {. }
$$

(Muskens 1996: p. 181, ex. 66)

If proper names are interpreted as dynamic generalized quantifiers as in (13), and the conjoined subject is interpreted via generalized dynamic conjunction as in (14), only one donkey will be available for subsequent anaphoric reference (in this case, the donkey associated with Sue). The reason is similar to (8): (12) ends up equivalent to Bill ${ }^{1}$ owns a donkey ${ }^{3}$, and Sue ${ }^{2}$ owns a donkey ${ }^{3}$, as in (15). The "second" occurrence of the indefinite erases the information

4 As two referees have pointed out, this analysis avoids under-generation by appealing to the syntax: for any utterance, the syntax generates a range of analyses compatible with its phonological form - here, analyses which assign different sequences of indices to the relevant constituents in a parse tree. This seems to be a relatively standard view of the division of labor between syntax and semantics, though I acknowledge that it is not universally shared (cf., e.g., Kamp \& Reyle 1993, Jacobson 1999, and others). It bears emphasizing, however, that the argument here does not strictly depend on a syntactic view of indexation. For my purposes, it would do just as well to view the syntactic inputs to semantic interpretation as index-free, i.e., as under-specified (see, e.g., Poesio 1996 and especially Muskens 2011). Systems of this kind could, in principle, resolve under-specification post-syntactically in ways that generate destructive updates, or in ways that do not. It seems, then, that the theoretical locus of indices and indexation is orthogonal to the destructive update issue. 
Where is the destructive update problem?

contributed by the "first". Moreover, the contra-indexing trick that helped with (8) is no help here, since there is just one indefinite to play with (at least, absent literal syntactic conjunction reduction). ${ }^{5}$

$$
\begin{aligned}
& \llbracket \text { Bill }^{1} \rrbracket=\lambda c \cdot \lambda g \cdot c \mathrm{~b} g^{1 \rightarrow \mathrm{b}} \quad \text { type: }(e \rightarrow s \rightarrow s \rightarrow t) \rightarrow s \rightarrow s \rightarrow t \\
& \llbracket \text { Bill }^{1} \text { and } S^{2} \mathrm{e}^{2} \rrbracket=\lambda c \cdot \lambda g \cdot \bigcup_{h \in c \text { b } g^{1 \rightarrow \mathrm{b}}} c \mathrm{~s} h^{2 \rightarrow \mathrm{s}} \\
& \lambda g .\left\{\left(g^{1 \rightarrow \mathrm{b}, 3 \rightarrow x}\right)^{2 \rightarrow \mathrm{s}, 3 \rightarrow y} \mid \text { donkey } x \wedge \text { owns } x \mathrm{~b} \wedge \text { donkey } y \wedge \text { owns } y \mathrm{~s}\right\}
\end{aligned}
$$

However, there are compelling reasons to pursue a different kind of analysis of such cases, one which does not inevitably write Bill's donkey out of the picture. Notably, a simple continuation like $i_{3}$ brays forces the widescope-indefinite reading of (12), on which there is a donkey that Bill and Sue own. There is no way to anaphorically target Bill's or Sue's individual donkeys on the wide-scope-and reading without making it clear which donkey we're interested in, for example with a locution like in Bill's case, it $t_{3}$ brays.

These facts closely parallel what's observed with indefinites under quantifiers like every linguist. This suggests that, as is frequently done for indefinites under quantifiers, we should associate the indefinite in the relevant interpretation of (12) with a parametrized (i.e., functional) discourse referent, as in (16) (Krifka 1996; see van den Berg 1996, Nouwen 2003, Brasoveanu 2007, 2008, and Solomon 2011 for related ideas). ${ }^{6}$ Here, the index 3 is mapped to a parametrized donkey D, 'intermediate' in a sense between Bill's and Sue's donkeys. Locutions like in Bill's case are one way to indicate how this parametric donkey is to be precisified.

$$
\begin{aligned}
\lambda g \cdot\left\{g^{1 \rightarrow \mathrm{b}, 2 \rightarrow \mathrm{s}, 3 \rightarrow \mathrm{D}} \mid \operatorname{DomD}=\{\mathrm{b}, \mathrm{s}\}\right. & \wedge \forall x \in \text { Dom } \mathrm{D}: \\
& \exists y \in \text { donkey: owns } y x \wedge \mathrm{D} x=y\}
\end{aligned}
$$

Despite initial appearances, then, constructions like (12) don't present undergeneration issues for dynamic theories with destructive update. Independently motivated analyses associate (12) with meanings like (16) rather than (15). And (16) harbors, in its own way, all the donkeys we could ever need.

5 Partializing the denotations of assignment-updating expressions in order to semantically enforce a novelty constraint, as in (10), does not solve this issue. In fact, it seems to leave us worse off: the prediction for such theories is that (12) is necessarily undefined. See Haug 2014 for pertinent discussion and a potential solution.

6 But see Bumford 2015 for another view. I leave it open how to relate sentential conjunction to the conjunction that figures in distributive quantification, as in (12). This topic seems under-investigated. 
Simon Charlow

\section{Over-generation?}

We might mount another sort of argument against destructive update. A linguist entered the room; a linguist was already there never has any readings that only serve up one of the two linguists for subsequent anaphora. That is, it just doesn't seem possible to interpret this text in a way that makes it impossible to refer back to the first-mentioned linguist. Yet if destructive updates are allowed, the LF in (8) generates precisely such an interpretation. Isn't that an over-generation problem?

There is something to this argument. Yet it cuts so deeply, against so many kinds of theories, that caution is warranted. For one, this sort of 'overgeneration' is seen in any theory that treats binding modularly - i.e., as the result of optional grammatical processes: if an operation necessary for binding applies optionally, it will always be possible to derive structures that 'erroneously' preclude in principle binding relationships that are possible i.e., structures in which the operation necessary for binding has not applied. Such modularity is characteristic of a huge swath of theories, from static assignment-based systems like Büring (2005), to sequence-based dynamic theories like the one advocated in Charlow (2014), to systems that eschew assignment functions entirely, like the variable-free treatments of Jacobson (1999) and Barker \& Shan (2014).

Moreover, even in static treatments of binding, it is possible to choose indices poorly, i.e., in ways that 'erroneously' rule out certain anaphoric relationships. Consider (17).

(17) Every linguist ${ }^{6}$ told every philosopher ${ }^{6}$ that she read $_{6}$ her $_{6}$ paper.

Here, two quantificational DPs bear the same index. Given standard assumptions about static interpretation (e.g., Heim \& Kratzer 1998, Büring 2005), only one of these DPs can bind the downstairs pronouns. If, for example, every linguist ${ }^{6}$ c-commands every philosopher ${ }^{6}$ at LF, as the quantifiers churn through linguists $x$ and philosophers $y$, the downstairs pronouns will be interpreted relative to doubly-shifted assignments $\left(g^{6 \rightarrow x}\right)^{6 \rightarrow y}$. These assignments map 6 only to the philosopher $y$-the linguist $x$ has been written out of the picture. As in the dynamic case, it is difficult to detect any such 'reading', one which positively prevents binding by both quantifiers.

7 In standard static theories, binding indices aren't borne directly by binders, but by abstraction nodes (e.g., Heim \& Kratzer 1998, Büring 2005). This doesn't affect the point: coindexed abstraction nodes can still step on each others' toes. See Section 7 for a theory with indexed binders. 
Where is the destructive update problem?

\section{The static/dynamic divide}

This is, of course, just to say that destructive assignment modification isn't the sole province of dynamic theories. The simplest static theories (e.g., Heim \& Kratzer 1998, Büring 2005) allow assignments to be over-written as the interpretation function recursively descends the tree. Unlike dynamic theories, in static systems the overwritten assignment is used only in the service of calculating denotations for phrase markers (crucially, those with free pronouns). Once this happens, the modified assignment flickers out of existence. Modified assignments, in other words, are only passed down the tree, to constituents c-commanded by whatever modified the assignment in the first place. ${ }^{8}$

In dynamic theories, by contrast, modified assignments are retained as components of semantic values. They aren't just passed down the tree; they live on as an observable record tracing (aspects of) how a sentence came to be associated with its meaning.

It's revealing to examine this point more formally. Consider Figure 1, an 'LF' for John saw Mary 5 . This tree is cleaved into two parts: everything below $\uparrow$, and everything above it. The idea is to separate things that interact with assignments (binders and pronouns) from things that don't. Below $\uparrow$, we have John, saw, and $t_{x} \cdot{ }^{9}$ Above $\uparrow$, we have (besides a $\lambda x$ binding the trace), the scoped-out, superscripted object Mary ${ }^{5}$. Superscripting is treated categorematically: ${ }^{5}$ turns Mary from a simple individual into a scope-taker that evaluates its scope relative to a shifted assignment - here, one mapping 5 to Mary (compare the dynamic entry for a proper name in (13)).

Doing functional application bottom-up yields $\lambda g$. $\uparrow(\mathrm{sawmj}) g^{5 \rightarrow \mathrm{m}}$ as the meaning of the sentence. What this amounts to turns on how we understand $\uparrow$. Two possibilities are given in Table 1 . The first - treating $\uparrow$ as a function that takes a truth value and an assignment and returns the truth valueyields a static proposition, a function from assignments to truth values (in this case, since the sentence contains no unbound pronouns, a constant func-

8 This is also, of course, how variable binding transpires in first-order logic and the $\lambda$-calculus. 9 N.B.: I intend Figure 1 as a logical form (that is, a semantic object) and not as a true LF. If this was a real LF, we'd of course have to say something about how the trace gets interpreted perhaps something involving assignments! I am choosing (largely for expository simplicity) to theorize about pronominal binding separately from whatever ties a scoped-out expression to its trace. Similar dissociations between pronominal and trace binding are seen in Muskens 1996: pp. 166-9, in Büring's (2005) distinction between $\beta$ and $\mu$ operators, and indeed in any semantic approach to scope (e.g., Hendriks 1993, Barker \& Shan 2014, Charlow 2014). 


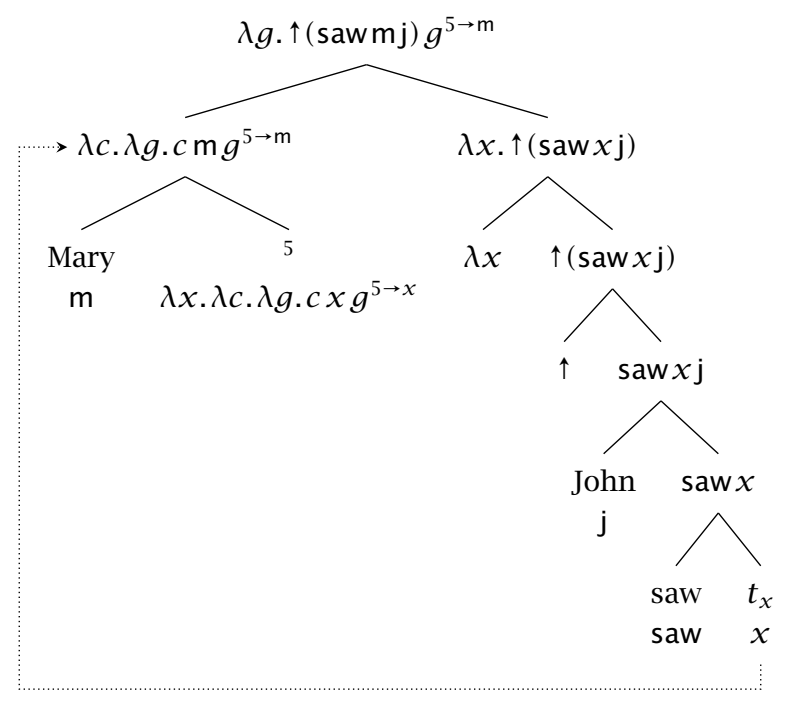

Figure 1: A modular perspective on static vs. dynamic semantics.

\begin{tabular}{lll}
\hline & Meaning for $\uparrow$ & Result for Figure 1 \\
\hline Static & $\lambda p \cdot \lambda \mathfrak{g} \cdot p$ & $\lambda \mathfrak{g} \cdot$ sawm \\
Dynamic & $\lambda p \cdot \lambda \mathfrak{g} \cdot\{\mathfrak{g}\}$ if $p$ else \{\} & $\lambda \mathfrak{g} \cdot\left\{\mathfrak{g}^{5 \rightarrow \mathrm{m}}\right\}$ if sawmj else \{\} \\
\hline
\end{tabular}

Table 1: Ways to get static and dynamic sentence meanings out of Figure 1. 
Where is the destructive update problem?

tion from assignments to truth values). The second - treating $\uparrow$ as a function that takes a truth value and an assignment, and returns the assignment, conditional on the truth value - yields a dynamic proposition, a relation on assignments. ${ }^{10}$

Simple-minded as it is, this modular approach to statics vs. dynamics turns out to be pretty flexible. We are free to superscript and scope out the subject in addition to the object. Static and dynamic meanings for indefinites and quantified expressions integrate seamlessly, as well (with the notable consequence that the quantifier's trace is what bears the binding superscript; I leave the details of this as an exercise). More relevantly for present purposes, if we wish to bind an in-scope pronoun, as in constructions like Polly $^{6}$ cited her ${ }_{6}$ paper, we can appeal to a lexical entry for pronominal expressions like (18) and a logical form like (19). With a static treatment of $\uparrow,(19)$ returns $\lambda g$. cited (paper $p) p$. With a dynamic-friendly $\uparrow,(19)$ yields $\lambda g .\left\{g^{6 \rightarrow p}\right\}$ if cited (paper $\left.p\right)$ p else \{\} .

$$
\begin{aligned}
& \llbracket \text { her }_{6} \rrbracket:=\lambda c . \lambda g . c g_{6} g \\
& \text { Polly }^{6}\left[\lambda x\left[\operatorname{her}_{6}\left[\lambda y\left[\uparrow\left[t_{x} \text { cited } t_{y} \text { 's paper }\right]\right]\right]\right]\right]
\end{aligned}
$$

From this point of view, then, the static/dynamic divide boils down to how we choose to think of $\uparrow$, the operator that builds a bridge between the parts of a sentence that care about assignment functions and the parts that do not. ${ }^{11}$ This in turn casts the static vs. dynamic perspectives on destructive updates into sharp relief. Consider the logical form in (20), an analysis of Polly ${ }^{5}$ gave Anna ${ }^{5}$ her $_{5}$ paper. It has two superscripted proper names jockeying for a single index. This triggers a succession of assignment function updates; the first associates 5 with Polly, and the second re-associates 5 with Anna. The pronoun is evaluated against this doubly-shifted assignment, and thus ends up denoting Anna. We end up with the possibly static, possibly

10 To obtain the continuized dynamic propositions of Dynamic Montague Grammar (e.g., Groenendijk \& Stokhof 1990, Zimmermann 1991, Chierchia 1995, Szabolcsi 2003, de Groote 2006), set $\llbracket \uparrow \rrbracket:=\lambda p . \lambda g . \lambda k . p \wedge k g$.

11 This division of labor (and logical form) between different 'kinds' of meaning, mediated by an operator like $\uparrow$, is reminiscent of Karttunen's (1977) analysis of questions (with $\uparrow$ playing a role analogous to Karttunen's proto-question rule). It is also characteristic of semantic theories based on the category-theoretic notion of a monad (Shan 2002). In fact, the static $\uparrow$ in Table 1 is monadic, though the dynamic $\uparrow$ isn't; a monadic, dynamic $\uparrow$ is $\lambda p . \lambda g .\{(p, g)\}$. In other work (Charlow 2014, 2020), I argue that monadic dynamic semantics has empirical virtues, including an account of exceptionally scoping indefinites (e.g., Fodor \& Sag 1982, Reinhart 1997). 
dynamic proposition in (21).

(20) $\operatorname{Polly}^{5}\left[\lambda x\left[\right.\right.$ Anna $^{5}\left[\lambda y\right.$ her $_{5}\left[\lambda z\left[\uparrow\left[t_{x}\right.\right.\right.$ gave $t_{y} t_{z}$ 's paper $\left.\left.\left.\left.\left.]\right]\right]\right]\right]\right]$

(21) $\lambda g \cdot \uparrow($ gavea (papera) $\mathrm{p})\left(g^{5 \rightarrow p}\right)^{5 \rightarrow a}$

The key difference between the static and dynamic approaches to $\uparrow$ is what happens to the destructively updated assignment. With a static $\uparrow$, it vanishes entirely: (21) reduces to (22). With a dynamic $\uparrow$, it's retained as an output: (21) reduces to (23).

(22) $\lambda g$.gavea (papera) $\mathrm{p}$

(23) $\lambda g \cdot\left\{\left(g^{5 \rightarrow p}\right)^{5 \rightarrow a}\right\}$ if gave a (papera) $p$ else \{\}

What this tells us is that the crucial difference between the static and dynamic perspectives on sentence meanings doesn't have much of anything to do with (destructive) assignment modification. As we move between the static and dynamic analyses of Figure 1, the treatment of assignment modification (i.e., superscripting) is invariant. In fact, the only thing that distinguishes the static analysis of Figure 1 from the dynamic one is the way in which $\uparrow$ is understood. A static $\uparrow$ uses modified assignments to fix the denotations of bound pronouns, and then summarily tosses them out. A dynamic $\uparrow$ retains these modified assignments for future use.

\section{Antisymmetry}

In this final section, I'll evaluate the idea that retaining and outputting destructively updated assignments via $\uparrow$ is problematic because it leads to failures of antisymmetry when two states are reachable from each other:

(24) $\quad h$ is reachable from $g, g \triangleleft h$, iff $h \in \llbracket \phi \rrbracket g$, for some $\phi$

The reachability relation is generally at least a preorder: $g$ is reachable from itself given the existence of a tautology (reflexivity); and if $g \triangleleft h$ via $\llbracket \phi \rrbracket$ and $h \triangleleft i$ via $\llbracket \psi \rrbracket$, then $g \triangleleft i$ via $\llbracket \phi . \psi \rrbracket$ (transitivity). But it is not always a partial order, since antisymmetry can fail. This is manifestly so in systems with destructive update: we might begin with an assignment mapping $n$ to $x$, overwrite $n$ to point to some new value $y$, and finally overwrite $n$ again to point to $x$, bringing us back where we started.

Why might this be problematic? Perhaps the most straightforward answer comes from the metasemantic gloss we give dynamic formalisms. Though 
Where is the destructive update problem?

our dynamic system inherits its approach to assignments and binding directly from our static system, using a dynamic $\uparrow$ means treating assignments as information, and not as mere preconditions for returning semantic values. Information growth is antisymmetric - at the very least, any putative failures of antisymmetry are unlikely to be a consequence of our narrow semantic competence. If we wish to use a dynamic $\uparrow$, we commit ourselves to treating assignments as information; if we then wish to update assignments, we should find a way to do so non-destructively. This is a reasonable view, though the arguments for it seem to be philosophical or metasemantic, rather than properly linguistic. ${ }^{12}$

We might, however, be able to leverage failures of antisymmetry to get empirical traction on the 'problems' of destructive update. Specifically, a certain incompatibility result is said to arise in dynamic systems where sentence meanings relate sets of points, and such relations may be non-distributivethat is, they may yield different results when an input set $s$ is processed whole and when $s$ is processed point-wise (van Benthem 1986, Groenendijk \& Stokhof 1991b): ${ }^{13}$

(25) $\quad \phi$ is distributive iff for all $s, \llbracket \phi \rrbracket s=\bigcup_{i \in s} \llbracket \phi \rrbracket\{i\}$

Various authors suggest that non-distributive dynamic systems must be antisymmetric. Groenendijk, Stokhof \& Veltman (1996: p. 195), for example, write that eschewing destructive update allows them to state their semantics "as an update semantics", by which they mean a non-distributive update system. The implication seems to be that destructive updates (and their concomitant antisymmetry) are problematic in non-distributive dynamic systems (see also Beaver 2002: p. 206). The next several paragraphs unpack this point before demonstrating that the problem can be defused.

Veltman's (1996) theory of epistemic modals is a paradigm case of a dynamic system with failures of distributivity (see also Groenendijk, Stokhof \& Veltman 1996, Aloni 1997, Beaver 2001, von Fintel \& Gillies 2007, Charlow

12 Another possibility is that failures of antisymmetry make the system 'too dynamic'. Rothschild \& Yalcin $(2016,2017)$, building on work by van Benthem (1986), prove that a system is 'weakly static' - that is, representable by intersective (i.e., Stalnakerian (1978)) systems with context-sensitivity - iff it is antisymmetric.

13 For the remainder of the paper we'll be dealing exclusively with functional relations. To simplify definitions, I abuse notation somewhat and write these values as functions. Similarly, dynamic conjunction is herewith re-conceptualized as function composition (in lieu

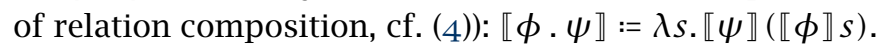


2021). Clauses for propositional atoms and epistemically modalized sentences are given in (26) and (27). The first updates $s$ by retaining only the points (possible worlds) where it rains. The second tests whether the prejacent $\phi$ is compatible with $s$; if so, $s$ is returned unchanged; otherwise, \{\} results.

$$
\begin{aligned}
& \llbracket \text { rain } \rrbracket:=\lambda s .\left\{i \in s \mid \operatorname{rain}_{i}\right\} \\
& \llbracket \text { might } \phi \rrbracket:=\lambda s .\{i \in s \mid \llbracket \phi \rrbracket s \neq\{\}\}
\end{aligned}
$$

Epistemically modal sentences are not generally distributive: e.g., if $w$ is a rain world, $v$ is not, and $s=\{w, v\}$, then $\llbracket$ might rain $\rrbracket s=s$, but $\bigcup_{i \in s} \llbracket$ might rain $\rrbracket\{i\}=\{w\}$.

Given this basic setup, it is possible (and desirable, as we'll see shortly) to define negation non-distributively, as in (28). This entry removes from $s$ the points that survive in $\llbracket \phi \rrbracket s$. This contrasts with (29), which distributively scans $s$ for individual points that trigger failure when updated with $\phi$. Thus, $\hat{\neg} \phi$ is always distributive, even when $\phi$ isn't.

$$
\begin{aligned}
& \llbracket \neg \phi \rrbracket:=\lambda s .\{i \in s \mid i \notin \llbracket \phi \rrbracket s\} \\
& \llbracket \hat{\neg} \phi \rrbracket:=\lambda s .\{i \in s \mid \llbracket \phi \rrbracket\{i\}=\{\}\}
\end{aligned}
$$

Only the non-distributive semantics in (28) gives good results for negated epistemic modal claims: $\neg$ might $\phi$ correctly requires that $\phi$ be incompatible with the input state $s$, whereas $A$ might $\phi$ merely eliminates the $\phi$-worlds from $s$ (e.g., Beaver 2001: pp. 155-6). ${ }^{14}$

Let's see how failures of distributivity look when anaphora is brought in. Dynamic accounts of anaphora and modality generally model contexts as sets of world-assignment pairs (e.g., Heim 1982, Groenendijk, Stokhof \& Veltman 1996). Sentences update these sets: (30) adds to $s$ the factual information that a man walked in the park (by eliminating worlds where no man did) and associates 3 with that man; (31) adds to $s$ the information that $g_{3}$ whistled; and (32) conjoins these two updates (see fn. 13), with (31) evaluated in the updated anaphoric context established by (30), as required for

14 If you're skeptical this is bad, note that (29) collapses negated epistemic possibility and

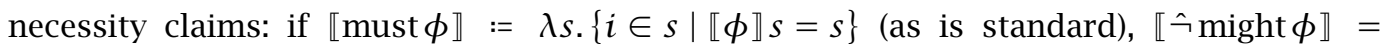
$\llbracket \hat{\neg} \operatorname{must} \phi \rrbracket=\{i \in s \mid \llbracket \phi \rrbracket\{i\}=\{\}\}$. 
Where is the destructive update problem?

dynamic binding.

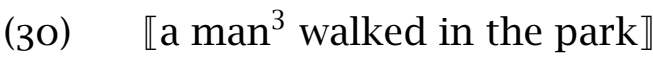

$$
=\lambda s \cdot\left\{\left(w, g^{3 \rightarrow x}\right) \mid(w, g) \in s \wedge \operatorname{man}_{w} x \wedge \operatorname{witp}_{w} x\right\}
$$

(31) $\llbracket$ he 3 whistled $\rrbracket=\lambda s .\left\{(w, g) \in s \mid \operatorname{whistled}_{w} g_{3}\right\}$

$$
\lambda s .\left\{\left(w, g^{3 \rightarrow x}\right) \mid(w, g) \in s \wedge \operatorname{man}_{w} x \wedge \operatorname{witp}_{w} x \wedge \operatorname{whistled}_{w} x\right\}
$$

The non-distributive might in (27) carries over immediately to this setting, with $i$ ranging over world-assignment pairs. But neither entry for negation works! The non-distributive (28) is a non-starter since the points in $s$ can be modified by $\phi$ (i.e., when a discourse referent is added). When this happens, very few (if any) of the points in $s$ will exist in $\llbracket \phi \rrbracket s$; the upshot in such cases would be to incorrectly trivialize negation. Meanwhile, the distributive (29) still incorrectly renders negated might-sentences distributive.

Crucially, however, an acceptable, non-distributive negation is easy to define in antisymmetric systems. Consider (33), which removes from $s$ the points with 'desendants' in $\llbracket \phi \rrbracket s$. Due to the occurrence of $\llbracket \phi \rrbracket s$ rather than $\llbracket \phi \rrbracket\{i\}$, the definition is non-distributive, as desired. Moreover, descendance allows us to remove the points from $s$ which subsist in $\llbracket \phi \rrbracket s$, without requiring those points to exist in $\llbracket \phi \rrbracket s$.

$$
\begin{aligned}
& \llbracket \neg \phi \rrbracket:=\lambda s .\left\{i \in s \mid \neg \exists i^{\prime} \in \llbracket \phi \rrbracket s: i \leqslant i^{\prime}\right\} \\
& (w, g) \leqslant(v, h) \text { iff } w=v \text { and } g \leqslant h
\end{aligned}
$$

Descendance comes quite cheap in any system whose contexts and points can be partially ordered, as seen in (34). By contrast, destructively updateable assignments can't be sensibly ordered by an antisymmetric relation: any two assignments with the same domains could in principle be descendants of each other, given enough updates. This is why non-distributive systems have sometimes been thought to necessitate antisymmetry.

But things are not so dire. On reflection, the argument against distributive negation (29) only establishes a relatively weak claim - i.e., that a dynamic account of modality and anaphora should be modally non-distributive. It has no direct bearing on whether assignments are processed distributively, too. And a distributive approach to assignments is sufficient for a well-behaved, non-distributive negation, with or without antisymmetry.

To state a semantics that is anaphorically distributive (but not modally so), we need only partition our contexts into equivalence classes with the 
same assignment, as in (35). We may then define epistemic modality and negation as in (36) and (37). ${ }^{15}$ These clauses work by partitioning $s$ under the same-assignments equivalence relation, updating the resulting $t \in$ Part $_{s}$ cells non-distributively with $\phi$, and using the resulting states to characterize the final output.

$$
\begin{aligned}
& \operatorname{Part}_{s}:=\operatorname{Max}\{t \subseteq s \mid \forall(w, g),(v, h) \in t: g=h\} \\
& \llbracket \operatorname{might} \phi \rrbracket:=\lambda s .\left\{i \in t \in \operatorname{Part}_{s} \mid \llbracket \phi \rrbracket t \neq\{\}\right\}
\end{aligned}
$$

Importantly, within any $t \in \operatorname{Part}_{s}$, each assignment is tagged with a $t$ unique world: any distinct $i, j \in t$ necessarily agree about their associated assignment, and so necessarily disagree about their associated world (otherwise $i$ and $j$ aren't distinct after all). This allows us to define negation using a notion of descendance based on equivalence of worlds, as in (37) and (38), in lieu of a partial order on points.

$$
\begin{aligned}
& \llbracket \neg \phi \rrbracket:=\lambda s .\left\{i \in t \in \operatorname{Part}_{s} \mid \neg \exists i^{\prime} \in \llbracket \phi \rrbracket t: i \approx i^{\prime}\right\} \\
& (w, g) \approx(v, h) \text { iff } w=v
\end{aligned}
$$

These definitions are anaphorically distributive, as defined in (39), but, as desired, they are not distributive tout court: if $s=\left\{\left(w, g^{3 \rightarrow x}\right),\left(v, g^{3 \rightarrow x}\right)\right\}$ and $x$ whistled in $w$ but not $v$, then $\llbracket$ might $\left[\right.$ he $_{3}$ whistled] $\rrbracket s=s$, but $\bigcup_{i \in s} \llbracket$ might $\left[\right.$ he $_{3}$ whistled $] \rrbracket\{i\}=\left\{\left(w, g^{3 \rightarrow x}\right)\right\}$.

(39) $\phi$ is anaphorically distributive iff for all $s, \llbracket \phi \rrbracket s=\bigcup_{t \in \text { Part }_{s}} \llbracket \phi \rrbracket t$

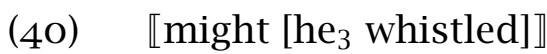

$$
=\lambda s .\left\{(w, g) \in t \in \operatorname{Part}_{s} \mid \llbracket \text { he }_{3} \text { whistled } \rrbracket t \neq\{\}\right\}
$$

Processing assignments distributively and worlds non-distributively dubbed 'slicing' by Aloni (1997) - is in essence the proposal of van Eijck \& Cepparello (1994), who themselves noted that it was consistent with destructive updates. ${ }^{16}$ There are substantive, non-trivial empirical issues in this

15 Notational point: ' $\left\{i \in t \in \operatorname{Part}_{s} \mid \phi\right\}$ ' names the set of $i$ such that: $\exists t \in \operatorname{Part}_{s}: i \in t \wedge \phi$.

16 The assignment-wise partitioning of contexts in the definitions of might and negation is admittedly a sort of complication, but it is an artifact of using the canonical dynamic representation of contexts (as sets of world-assignment pairs). The actual proposal of van Eijck \& Cepparello models sentence meanings as relations between two assignments (anaphoric contexts) and two sets of worlds (modal contexts), which entails that assignments are processed distributively, while allowing sets of worlds to be processed non-distributively. (According to van Eijck \& Cepparello (1994), this system was pioneered in a pre-final draft of Dekker 1993, who termed it the 'least common product' of dynamic accounts of anaphora and modality.) 
Where is the destructive update problem?

vicinity. Anaphoric distributivity was criticized by Groenendijk, Stokhof \& Veltman (1996: p. 213), who pointed out that it rendered cases like (41) contradictory. This data was called into question by Büring (1998), who argued that such examples were reduced clefts, noting that versions like (42) with the expected third-person pronouns do in fact sound contradictory (see also Mikkelsen 2005).

(41) Someone has done it. It might be you. But it might also not be you.

(42) Someone has done it. \#He might be you. \#But he might also not be you.

Can we at least conclude conditionally, then, that if Groenendijk, Stokhof \& Veltman are right about (41), destructive updates are problematic? Afraid not! For there are other ways to chop up a context which are neither anaphorically nor modally distributive, and which are compatible with failures of antisymmetry. We may divide $s$ into sub-states with the same informational content as $s$ and which do not duplicate worlds, as in (43) (cf. Beaver 1997: p. 975). Or, following Aloni (1997, 2001), we may divide $s$ via a conceptual cover $C C$, a contextually determined set of disjoint individual concepts that exhaustively covers the domain, as in (44). (Readers are referred to Aloni's work for details; Aloni herself notes (2001: 94) that 'slicing' via conceptual covers renders destructive updates unproblematic.) On any of these approaches, any assignment in a cell $t$ is tagged with a $t$-unique world, which allows us to bootstrap a notion of descendance as in (37) and (38). ${ }^{17}$

$$
\begin{aligned}
& \operatorname{Part}_{s}^{\text {info }}:=\left\{t \subseteq s \mid \forall w \in \text { worlds }_{s}: \exists !(v, g) \in t: v=w\right\} \\
& \operatorname{Part}_{s}^{C C}:=\operatorname{Max}\{t \subseteq s \mid \exists c \in C C: \forall(w, g) \in t: \\
& \left.\qquad n \in \text { Domg: } g_{n}=c_{w}\right\}
\end{aligned}
$$

Thus, it is difficult to locate any deep, inherent incompatibility between failures of distributivity and failures of antisymmetry. Failures of modal distributivity are consistent with anaphoric distributivity (35), or with various forms of quasi-distributivity induced, e.g., by (43) and (44). As this suggests, one way to provide evidence against destructive update would be to provide evidence against each of these ways of re-organizing the context, but such evidence has to my knowledge not been provided in the literature.

17 To be clear, despite the carried-over notation, neither of these latter two approaches necessarily partitions $s$. 
The interaction of distributivity and antisymmetry has relevance beyond the destructive update 'problem'. For the putative incompatibility result I've challenged here holds that failures of distributivity are incompatible with failures of antisymmetry, wherever such failures arise. Consider in this vein a dynamic system like Dekker's (1994), where anaphoric information is stored in monotonically updated sequences, and discourse referent introduction amounts to sequence extension. Now consider a related system, in which sequences can be extended, but also re-ordered, with reordering corresponding, perhaps, to shifts in the relative prominence of discourse referents (cf., e.g., Grosz, Joshi \& Weinstein 1995, Bittner 2001, Murray 2014, Stojnić, Stone \& Lepore 2017).

This latter sort of system lacks destructive updates, but might fail to be antisymmetric. For example, the sequence $x^{-} y$ might be reordered by some sequence of updates to $y^{-} x$ and then back to $x^{-} y$. That is, we begin with $x$ as the most prominent referent; $y$ subsequently takes the mantle; and $x$ is finally restored. If, as I've argued, notions of descendance on points can be defined which tolerate non-antisymmetric transitions between points, then such a system is consistent with failures of distributivity as well.

\section{References}

Aloni, Maria. 1997. Quantification in dynamic semantics. In Paul Dekker, Martin Stokhof \& Yde Venema (eds.), Proceedings of the Eleventh Amsterdam Colloquium, 73-78. Amsterdam: Institute for Logic, Language \& Computation (ILLC), University of Amsterdam.

Aloni, Maria. 2001. Quantification under conceptual covers. University of Amsterdam Ph.D. thesis. http://hdl.handle.net/11245/1.173339.

Barker, Chris \& Chung-chieh Shan. 2014. Continuations and natural language. Oxford: Oxford University Press. https://doi.org/10.1093/acprof:oso/ 9780199575015.001.0001.

Barwise, Jon. 1987. Noun phrases, generalized quantifiers, and anaphora. In Peter Gärdenfors (ed.), Generalized Quantifiers, 1-29. Dordrecht: Reidel. https://doi.org/10.1007/978-94-oo9-3381-1_1.

Beaver, David I. 1997. Presupposition. In Johan van Benthem \& Alice ter Meulen (eds.), Handbook of logic and language, chap. 17, 939-1008. Amsterdam: North-Holland. https : / / doi . org / 10 . 1016 / B978 - 044481714 3/50022-9. 
Where is the destructive update problem?

Beaver, David I. 2001. Presupposition and assertion in dynamic semantics. Stanford: Center for the Study of Language \& Information (CSLI) Publications. https://semanticsarchive.net/Archive/jU1MDVmZ/.

Beaver, David I. 2002. Pragmatics, and that's an order. In David BarkerPlummer, David I. Beaver, Johan van Benthem \& Patrick Scotto di Luzio (eds.), Words, Proofs and Diagrams, 191-216. Stanford: Center for the Study of Language \& Information (CSLI) Publications.

van Benthem, Johan. 1986. Essays in logical semantics. Dordrecht: Reidel. https://doi.org/10.1007/978-94-009-4540-1.

van den Berg, Martin H. 1996. Some aspects of the internal structure of discourse: The dynamics of nominal anaphora. University of Amsterdam Ph.D. thesis. https:// eprints .illc. uva.nl/id/eprint/1996/1/DS - 1996 o3.text.pdf.

Bittner, Maria. 2001. Surface composition as bridging. Journal of Semantics 18(2). 127-177. https://doi.org/10.1093/jos/18.2.127.

Brasoveanu, Adrian. 2007. Structured nominal and modal reference. Rutgers University Ph.D. thesis. http://semanticsarchive.net/Archive/TFjZGZjN/.

Brasoveanu, Adrian. 2008. Donkey pluralities: Plural information states versus non-atomic individuals. Linguistics and Philosophy 31(2). 129-209. https://doi.org/10.1007/s10988-008-9035-o.

Bumford, Dylan. 2015. Incremental quantification and the dynamics of pairlist phenomena. Semantics and Pragmatics 8(9). 1-70. https://doi.org/10. 3765/sp.8.9.

Büring, Daniel. 1998. Identity, modality, and the candidate behind the wall. In Devon Strolovitch \& Aaron Lawson (eds.), Proceedings of Semantics and Linguistic Theory 8, 36-54. Ithaca, NY: Cornell University. https:// doi. org/10.3765/salt.v8io.2805.

Büring, Daniel. 2005. Binding theory. New York: Cambridge University Press. https://doi.org/10.1017/cbo9780511802669.

Charlow, Simon. 2014. On the semantics of exceptional scope. New York University Ph.D. thesis. https://semanticsarchive.net/Archive/2JmMWRjY/ charlow-semantics-exceptional-scope-diss.pdf.

Charlow, Simon. 2020. The scope of alternatives: Indefiniteness and islands. Linguistics and Philosophy 43. 427-472. https://doi.org/10.1007/s10988o19-09278-3.

Charlow, Simon. 2021. Post-suppositions and semantic theory. https://ling. auf.net/lingbuzz/oo3243. (Accepted at Journal of Semantics). 
Chierchia, Gennaro. 1995. The dynamics of meaning: Anaphora, presupposition and the theory of grammar. Chicago: University of Chicago Press. https://doi.org/10.7208/chicago/9780226104515.001.0001.

Dekker, Paul. 1993. Transsentential meditations: Ups and downs in dynamic semantics. University of Amsterdam Ph.D. thesis. http://hdl.handle.net/ 11245/1.392554.

Dekker, Paul. 1994. Predicate logic with anaphora. In Mandy Harvey \& Lynn Santelmann (eds.), Proceedings of Semantics and Linguistic Theory 4, 7995. Ithaca, NY: Cornell University. https://doi.org/10.3765/salt.v4io.2459. van Eijck, Jan. 200o. The proper treatment of context in NL. In Paola Monachesi (ed.), Computational Linguistics in the Netherlands (CLIN) 1999: Selected papers from the Tenth CLIN Meeting, 41-51. Utrecht Institute of Linguistics, OTS. https://www. clinjournal. org/CLIN_proceedings/X/ vaneijck.pdf.

van Eijck, Jan. 2001. Incremental dynamics. Journal of Logic, Language and Information 10(3). 319-351. https://doi.org/10.1023/A:1011251627260.

van Eijck, Jan \& Giovanna Cepparello. 1994. Dynamic modal predicate logic. In Makoto Kanazawa \& Christopher J. Piñon (eds.), Dynamics, polarity, and quantification, 251-276. Stanford: Center for the Study of Language \& Information (CSLI) Publications.

von Fintel, Kai \& Anthony S. Gillies. 2007. An opinionated guide to epistemic modality. In Tamar Szabo Gendler \& John Hawthorne (eds.), Oxford studies in epistemology, vol. 2, 32-62. Oxford: Oxford University Press.

Fodor, Janet Dean \& Ivan A. Sag. 1982. Referential and quantificational indefinites. Linguistics and Philosophy 5(3). 355-398. https://doi.org/10.1007/ BFoo351459.

Geurts, Bart. 2000. Indefinites and choice functions. Linguistic Inquiry 31(4). 731-738. https://doi.org/10.1162/002438900554550.

Groenendijk, Jeroen \& Martin Stokhof. 1990. Dynamic Montague grammar. In Laszlo Kalman \& Laszlo Polos (eds.), Proceedings of the Second Symposium on Logic and Language, 3-48. Budapest: Eötvös Loránd University Press. https://hdl.handle.net/11245/1.428383.

Groenendijk, Jeroen \& Martin Stokhof. 1991a. Dynamic predicate logic. Linguistics and Philosophy 14(1). 39-100. https:// doi .org / 10.1007 / BFoo628304.

Groenendijk, Jeroen \& Martin Stokhof. 1991b. Two theories of dynamic semantics. In Jan van Eijck (ed.), Logics in AI: European workshop JELIA '9o Amsterdam, The Netherlands, September 10-14, 1990 proceedings, 55-64. 
Where is the destructive update problem?

Berlin, Heidelberg: Springer Berlin Heidelberg. https://doi.org/10.1007/ BFboo18433.

Groenendijk, Jeroen, Martin Stokhof \& Frank Veltman. 1996. Coreference and modality. In Shalom Lappin (ed.), The Handbook of Contemporary Semantic Theory, 179-216. Oxford: Blackwell. https://hdl.handle.net/11245/1. 123522.

de Groote, Philippe. 2006. Towards a Montagovian account of dynamics. In Masayuki Gibson \& Jonathan Howell (eds.), Proceedings of Semantics and Linguistic Theory 16, 1-16. Ithaca, NY: Cornell University. https://doi.org/ 10.3765/salt.v16io.2952.

Grosz, Barbara J., Aravind K. Joshi \& Scott Weinstein. 1995. Centering: A framework for modeling the local coherence of discourse. Computational Linguistics 21(2). 203-225. https://www.aclweb.org/anthology/J95-2003.

Haug, Dag Trygve Truslew. 2014. Partial dynamic semantics for anaphora: Compositionality without syntactic coindexation. Journal of Semantics 31(4). 457-511. https://doi.org/10.1093/jos/fftoo8.

Heim, Irene. 1982. The semantics of definite and indefinite noun phrases. University of Massachusetts, Amherst Ph.D. thesis. https://semanticsarchive. net/Archive/TkoZmYyY/dissertation.pdf.

Heim, Irene. 2011. Definiteness and indefiniteness. In Klaus von Heusinger, Claudia Maienborn \& Paul Portner (eds.), Semantics: An international handbook of natural language meaning, vol. 2 (Handbooks of Linguistics and Communication Science (HSK) 33), chap. 41, 996-1025. Berlin: de Gruyter. https://doi.org/10.1515/9783110255072.996.

Heim, Irene \& Angelika Kratzer. 1998. Semantics in generative grammar. Oxford: Blackwell.

Hendriks, Herman. 1993. Studied flexibility: Categories and types in syntax and semantics. University of Amsterdam Ph.D. thesis.

Jacobson, Pauline. 1999. Towards a variable-free semantics. Linguistics and Philosophy 22(2). 117-184. https://doi.org/10.1023/A:1005464228727.

Kamp, Hans. 1981. A theory of truth and semantic interpretation. In Jeroen Groenendijk, Theo M. V. Janssen \& Martin Stokhof (eds.), Formal Methods in the Study of Language, 277-322. Mathematical Centre Amsterdam. (Republished in Kamp 2013).

Kamp, Hans. 2013. A theory of truth and semantic interpretation. In Klaus von Heusinger \& Alice ter Meulen (eds.), Meaning and the Dynamics of Interpretation, vol. 29, 329-369. Leiden, The Netherlands: Brill. https:// doi.org/10.1163/9789004252882_014. 
Kamp, Hans \& Uwe Reyle. 1993. From Discourse to Logic. Dordrecht: Kluwer Academic Publishers.

Karttunen, Lauri. 1977. Syntax and semantics of questions. Linguistics and Philosophy 1(1). 3-44. https://doi.org/10.1007/BFoo351935.

Kratzer, Angelika. 1998. Scope or pseudoscope? Are there wide-scope indefinites? In Susan Rothstein (ed.), Events and grammar, vol. 70 (Studies in Linguistics and Philosophy), 163-196. Springer Netherlands. https://doi. org/10.1007/978-94-011-3969-4_8.

Krifka, Manfred. 1996. Parametrized sum individuals for plural anaphora. Linguistics and Philosophy 19(6). 555-598. https:// doi.org / 10.1007 / BFoo632708.

Lebedeva, Ekaterina. 2012. Expressing discourse dynamics through continuations. Université de Lorraine Ph.D. thesis. https://theses.hal.science/telo1749193.

Mikkelsen, Line. 2005. Copular clauses: Specification, predication and equation. Vol. 85 (Linguistik Aktuell/Linguistics Today). Amsterdam/Philadelphia: John Benjamins. https://doi.org/10.1075/la.85.

Murray, Sarah E. 2014. Varieties of update. Semantics and Pragmatics 7(2). 1-53. https://doi.org/10.3765/sp.7.2.

Muskens, Reinhard. 1996. Combining Montague semantics and discourse representation. Linguistics and Philosophy 19(2). 143-186. https:// doi . org/10.1007/BFoo635836.

Muskens, Reinhard. 2011. A squib on anaphora and coindexing. Linguistics and Philosophy 34(1). 85. https://doi.org/10.1007/s10988-011-9091-8.

Nouwen, Rick. 2003. Plural pronominal anaphora in context (Netherlands Graduate School of Linguistics Dissertations 84). Utrecht: LOT. https: //dspace.library.uu.nl/handle/1874/630.

Nouwen, Rick. 2007. On dependent pronouns and dynamic semantics. Journal of Philosophical Logic 36(2). 123-154. https://doi.org/10.1007/s10992oo6-9029-8.

Nouwen, Rick, Adrian Brasoveanu, Jan van Eijck \& Albert Visser. 2016. Dynamic Semantics. In Edward N. Zalta (ed.), The Stanford Encyclopedia of Philosophy, Fall 2016. http://plato.stanford.edu/entries / dynamic semantics/.

Poesio, Massimo. 1996. Semantic ambiguity and perceived ambiguity. In Kees van Deemter \& Stanley Peters (eds.), Semantic Ambiguity and Underspecification (Center for the Study of Language and Information Lecture Notes 
Where is the destructive update problem?

55), 159-201. Stanford: Center for the Study of Language \& Information (CSLI) Publications. https://doi.org/10.48550/arXiv.cmp-lg/9505034.

Reinhart, Tanya. 1997. Quantifier scope: How labor is divided between QR and choice functions. Linguistics and Philosophy 20(4). 335-397. https: //doi.org/10.1023/A:1005349801431.

Rooth, Mats. 1987. Noun phrase interpretation in Montague grammar, File Change Semantics, and situation semantics. In Peter Gärdenfors (ed.), Generalized Quantifiers, 237-269. Dordrecht: Reidel. https:// doi.org / 10.1007/978-94-009-3381-1_9.

Rothschild, Daniel \& Seth Yalcin. 2016. Three notions of dynamicness in language. Linguistics and Philosophy 39(4). 333-355. https://doi.org/10.1007/ s10988-016-9188-1.

Rothschild, Daniel \& Seth Yalcin. 2017. On the dynamics of conversation. Noûs 51(1). 24-48. https://doi.org/10.1111/nous.12121.

Shan, Chung-chieh. 2002. Monads for natural language semantics. In Kristina Striegnitz (ed.), Proceedings of the 2001 European Summer School in Logic, Language and Information (ESSLLI) student session, 285-298. https://doi. org/10.48550/arXiv.cs/0205026.

Solomon, Michael. 2011. True distributivity and the functional interpretation of indefinites. http:// semanticsarchive. net/Archive/zkxN2M4M/ solomon-functional-indefinites.pdf. (Unpublished ms.).

Stalnaker, Robert. 1978. Assertion. In Peter Cole (ed.), Pragmatics, vol. 9 (Syntax and Semantics), 315-332. New York: Academic Press. https://doi.org/ 10.1163/9789004368873_013.

Stojnić, Una, Matthew Stone \& Ernie Lepore. 2017. Discourse and logical form: Pronouns, attention and coherence. Linguistics and Philosophy 40(5). 519547. https://doi.org/10.1007/s10988-017-9207-x.

Szabolcsi, Anna. 2003. Binding on the fly: Cross-sentential anaphora in variable-free semantics. In Geert-Jan M. Kruijff \& Richard T. Oehrle (eds.), Resource-sensitivity, binding and anaphora, chap. 8, 215-227. Dordrecht: Kluwer Academic Publishers. https://doi.org/10.1007/978-94-010-0037$6 \_8$.

Veltman, Frank. 1996. Defaults in update semantics. Journal of Philosophical Logic 25(3). 221-261. https://doi.org/10.1007/BFoo248150.

Vermeulen, C. F. M. 1993. Sequence semantics for dynamic predicate logic. Journal of Logic, Language and Information 2(3). 217-254. https://doi . org/10.1007/BFo1050788. 
Vermeulen, C. F. M. 1995. Merging without mystery or: Variables in dynamics semantics. Journal of Philosophical Logic 24(4). 405-450. https://doi.org/ 10.1007/BFo1048354.

Zimmermann, Thomas Ede. 1991. Dynamic logic and case quantification. In Martin Stokhof, Jeroen Groenendijk \& David Beaver (eds.), Quantification and Anaphora I (DYANA Deliverable R2.2.A), 191-195.

\author{
Simon Charlow \\ Department of Linguistics \\ Rutgers, The State University of New Jersey \\ 18 Seminary Place \\ New Brunswick, NJ o8901 \\ simon.charlow@rutgers.edu
}

